\title{
Book Review: Online Privacy: Issues in the Digital Age
}

Darlene M. Tester

Metropolitan State University

Follow this and additional works at: https://commons.erau.edu/jdfs|

Part of the Computer Engineering Commons, Computer Law Commons, Electrical and Computer Engineering Commons, Forensic Science and Technology Commons, and the Information Security Commons

\section{Recommended Citation}

Tester, Darlene M. (2011) "Book Review: Online Privacy: Issues in the Digital Age," Journal of Digital Forensics, Security and Law. Vol. 6 : No. 3 , Article 6.

DOI: https://doi.org/10.15394/jdfsl.2011.1101

Available at: https://commons.erau.edu/jdfsl/vol6/iss3/6

This Article is brought to you for free and open access by the Journals at Scholarly Commons. It has been accepted for inclusion in Journal of Digital Forensics, Security and Law by an authorized administrator of Scholarly Commons. For more information, please contact commons@erau.edu. 


\title{
BOOK REVIEWS
}

\author{
Jigang Liu \\ Editor \\ Metropolitan State University \\ St. Paul, MN 55106 \\ Jigang.Liu@metrostate.edu
}

If you have any suggestions on books for review, or you would like to write a book review for us, or you have any comments and concerns on the book reviews published on this column, please feel free to send an email to Jigang Liu at Jigang.Liu@metrostate.edu.

\section{BOOK REVIEW}

Currie, Stephen (2012): Online Privacy: Issues in the Digital Age, San Diego, CA, Reference Point Press, Inc. 96 pages, ISBN: 13-978-1-60152-194-1, US $\$ 27.95$.

Reviewed by Darlene M Tester, CISSP, CISM, ITIL, CHSS, JD, Metropolitan State University, Minnesota (nonsequitr60@gmail.com)

This book is one of a series of books Currie has written about online areas of concern. This is the sixth book in the series. The purpose of the book is to act as a primer for people in the IT field who may need a point of reference for Internet issues such as gaming, security and privacy. The book takes a high level look at the complexities of privacy online from social networking to hackers and provides insight into what the most pressing issues of privacy are online today.

The book has an introduction and five chapters, then sections on source notes, a fact sheet on privacy, and a series of research sources for further information. The book provides excellent case law related to the issues of trying to protect the privacy of yourself as well as your customer online. In addition it talks about assumptions made by Internet users that organizations doing business online must take into account such as the assumption that all credit card transactions are secure or that all data provided by them to a company are secure.

In the first chapter, Currie discusses the situation of a Pennsylvania school district that handed out laptops to all students at the beginning of the school year. Later in the year it was discovered that each laptop had a built in camera by which the school could monitor student behavior. The school assistant principal had taken this concept too far when she began monitoring student behavior in their homes. This sets the stage for a review of what privacy expectation truly is; if the devices are owned by the school is there an expectation of privacy, etc. This is an excellent way to lay a foundation of online privacy issues.

There's an excellent chart on page 19 that identifies online activities by age of the 
user. While the fact that the young use the Internet for many every day things, the more amazing statistic on the chart is that people over the age of 70 are using the Internet more; everything from email to online banking. It shows the cultural changes however from young to old in the types of Internet usage.

In the second chapter, Currie discusses social networking and the concepts of Facebook, Twitter, and other means of 'meeting' people online. He looks at the fact that we provide an enormous amount of personal information on these sites and wonders how we, as a society, can believe we have privacy if we so willingly provide this information to the world. He also goes over the issues of cyberbullying and the fact that more employers are turning to social networking pages to make determinations on candidates for hire. His statistic is that "onethird of companies that check applicants' social networking sites have rejected candidates based on something they posted."

In the third chapter, Currie delves into the corporate world and how it handles the privacy of its customers and employees. There is a bit of a "big brother" scare to the writing by adding the fact that Apple can now track anyone who owns an iPhone or iPad. The tracking issues that are described in the book are too focused on the bad part of the tracking capability without ever showing that tracking software has been used for anything other than what is was made to do - provide security for lost devices and provide customer preference in shopping. There's only a small inset about opt-in/opt-out; this should have been covered in more depth as most companies today must meet separate state laws related to opt-out features on the Internet.

The biggest topic of this chapter is Google Street View. In 2007 Google launched an online feature called Google Street View. Basically Google sent people out with special cameras to get the street-level view of communities found on Google Maps. The issue is that some areas that were photographed were private property, other photos had people in them and those photos were used without the permission of the people who can be seen in them. This creates not only privacy issues, but legality issues as well. The most interesting story comes from North Oaks, MN and the fact that all of their streets are private streets.

Chapter four covers how the governments have been chipping away at our privacy over time. Currie begins the chapter with a reference to George Orwell's Nineteen Eighty-Four to define how he sees government surveillance of its citizens. He talks about the mistrust citizens have in government and brings up several instances of government 'meddling' that has created that mistrust - like taxing authorities and motor vehicle licensing agencies asking for all sorts of private information about the citizen. He covers the Patriot Act and brings up Santa Cruz library's warning sign inside the door that tells all who enter that the Patriot Act allows the federal government to obtain information about all of the books you borrow from the library. Currie's view of government surveillance is akin to George Orwell's idea of government intervention. 
Currie finishes the book with a chapter on hackers. Currie covers hackers at a high level touching on the Sony Playstation hacker in 2011. He talks about the price of identities on the black market and describes the process for using the information to create alternate accounts that will be used for a short period of time to drain money and credit from another person's identity. He covers a variety of means of obtaining information including phishing and password cracking. Currie has some interesting statistics using Rogelio Hackett's crime spree that allegedly netted him over \$30 million in fraudulent charges.

On the whole, the book is a good primer for someone wanting to know more (at a high level) of what issues a company or individual may face on the Internet related to data privacy. The resources Currie adds at the back of his book are good research resources for more information on privacy and the Internet. There are some issues with the author relating too much of his own personal opinion about data collection and security and selecting those stories and cases that draw out the fact that privacy is not an option on the Internet, but Currie covers the topic well from types of data collected to issues consumers will have providing the information and issues corporations will having in taking and storing that information. 
Journal of Digital Forensics, Security and Law, Vol. 6(3) 